\title{
HUBUNGAN PEKERJAAN IBU DENGAN MINAT KUNJUNGAN POSYANDU BALITA DI DESA NAWANGAN KABUPATEN PACITAN
}

\author{
Murniati $^{1)}$, Nurhayati ${ }^{2)}$ \\ Akbid Harapan Mulya Ponorogo ${ }^{12)}$
}

Abstract

\begin{abstract}
From data at Posyandu Nawangan Nawangan Village, Nawangan sub-district, Pacitan number of Mother visit to Posyandu is 151 from 222 mothers. While.Bassed preface study which have done on November 2016, that have doing some interview with 10 persons, 7 persons of them (70 percent) have professions as (4 are entrepreneur, 2 are farmer, and 1 is a civil servant), and 3 persons (30\%) are housewife. From 7 persons (100\%) who are laborer all of them do not interest to visit pposyandu with the reason that they do not have any time because they must go to work. So, a child with mother as a laborer probability will make effect to the balita while visit posyandu. The goal of the research is to find out the relation of mother's professions with interesting to visit Posyandu in nawangan village, nawangan subdistrict, pacitan regency.

This research is kind of quantitative research approach by correlational and planning os cross sectional. Population of this research is all of the balita's mother on February 2017 in posyandu nawangan village,nawangan subdistrict, pacitan regency on February 2017 total 222 person and the sample total 83 persons with technique sampling is accidental sampling. Variable dipenden mother's professions of balita and variable dependent the interesting to visit posyandu. The instrument uses questionair. Statistic experiment with chi square in standart significant 0,05 .

Based on the result of the research has getting that balita's mother most of 51 respondent $(61,4 \%)$ are laborer. Interesting to visit posyandu of mother who have balita most of 71 respondens (85.5\%) with negative interesting. There is relation between mother's profession with interesting to visit posyandu balita in nawangan village, nawangan subdistrict, pacitan regency,,$p$ value $=0,031$ sop $<$ a 0,05 the result reported Ho has rejected $\mathrm{H} 1$ has accepted and correlation coefisient $=0,231$ that means the firm level is low.

The result of research has expected able to give information to balita's mother about the important of posyandu balita observe grow up of balita and as a facilities to get information and communication with local paramedis.
\end{abstract}

Key Word: Interest, Posyandu, mother, toodler

\section{PENDAHULUAN}

Keberhasilan posyandu tergambar melalui cakupan SKDN dimana (S) merupakan seluruh jumlah balita diwilayah kerja posyandu, (K) jumlah semua balita yang memiliki KMS, (D) balita yang ditimbang, (N) balita yang berat badannya naik. Dari data D/S tergambar baik atau kurangnnya peran serta masyarakat dalam pengunaan posyandu (Depkes RI, 2004).

Angka Kematian Balita (AKABA) Kabupaten Pacitan ditahun 2014 yaitu 76 balita (Profil Dinkes Jatim, 2014). Berdasarkan data di posyandu Nawangan
Desa Nawangan Kecamatan Nawangan Kabupaten Pacitan pada bulan oktober 2016 didapatkan 222 ibu balita dan yang datang ke posyandu pada bulan oktober 2016 yaitu 151 , jumlah posyandu ada 5 jumlah balita ditahun 2016 sebanyak 222 balita, terdiri dari 150 balita laki-laki dan 72 balita perempuan, pencapaian SKDN pada pos 1 dengan jumlah balita 23 yaitu $82,60 \%$, pos 2 dengan jumlah balita 31 yaitu $74,19 \%$, pos 3 jumlah balita 33 yaitu $72,72 \%$, pos 4 jumlah balita 42 yaitu $66,66 \%$, pos 5 jumlah balita 93 yaitu $61,29 \%$. 
Pencapain penimbangan pada tahun 2016 adalah 151 yaitu 68,01\% dari target 100\%. Cakupan SKDN di Desa Nawangan Kecamatan Nawangan Kabupaten Pacitan pada tahun 2016 adalah pencapaian penimbangan balita yaitu : D/S x 100\% sebesar 151 yaitu $68,01 \%, \mathrm{~K} / \mathrm{S} \times 100 \%$ sebesar 184 yaitu $82,88 \%$, N/D x $100 \%$ sebesar 95 yaitu $62,91 \%$.

Berdasarkan studi pendahuluan yang telah dilakukan pada Bulan November 2016, dengan wawancara pada 10 orang didapatkan 7 orang $(70 \%)$ dengan bekerja (4 swasta, 2 tani dan 1 PNS), dan 3 orang (30\%) tidak bekerja (IRT). Dari 7 orang $(100 \%)$ yang bekerja didapatkan seluruhnya tidak minat melakukan kunjungan posyandu dengan alasan tidak ada waktu karena harus bekerja. Sehingga dengan ibu yang bekerja memungkinkan akan mempengaruhi minat dalam melakukan kunjungan posyandu pada balita.

Faktor-faktor yang mempengaruhi minat meliputi : umur, pendidikan, pekerjaan dan jarak rumah (Andryana, 2015). Sedangkan faktor-faktor yang mempengaruhi kunjungan ibu balita ke posyandu diantaranya pengetahuan ibu, umur balita, pekerjaan ibu, jarak rumah, dan fasilitas (Agustina, 2013).

Dampak yang terjadi pada ibu yang tidak efektif datang keposyandu adalah balitanya bisa terkena gizi buruk, karena ibu yang tidak memeriksakan kondisi balita diposyandu setiap bulannya, imunisasi yang tidak memenuhi target, kemungkinan besar juga dapat terkena ISPA, dan akan sering sakit karena kurang mendapatkan bimbingan dan pengawasan. Beberapa factor yang berhubungan dengan ketidakaktifan ibu balita untuk berkunjung ke posyandu antara lain: pendidikan, status pekerjaan, tingkatan pendapatan, tingkat pengetahuan, umur balita, jumlah balita, umur balita, jarak keposyandu, dan sarana penunjang (Sutrismang, 2010: 17-22).

Dampak yang terjadi di Desa Nawangan Kecamatan Nawangan Kabupaten Pacitan dari 7 orang yang tidak minat melakukan kunjungan posyandu didapatkan dengan jumlah kunjungan tidak aktif setiap bulannya, sehingga pada balitanya tidak terpantau pertumbuhan dan perkembangan, selain itu pada balita sering mengalami penyakit seperti panas, batuk, pilek.

Solusi yang dapat dilakukan untuk meningkatkan minat melakukan kunjungan posyandu adalah dengan meningkatkan pengetahuannya tentang manfaat kegiatan posyandu, salah satunya adalah untuk bimbingan dan pengawasan terhadap anaknya. Kebutuhan anak balita dalam masanya adalah kebutuhan fisikbiomedis ("ASIH") (penimbangan secara teratur, imunisasi,pengobatan), kebutuhan emosi dan kasih sayang (“ASUH") kasih sayang orang tua akan meningkatkan ikatan yang erat, kebutuhan akan stimulasi dan mental ("ASAH") akan mengembangkan kecerdasan, kemandirian dan kepribadian (Ismawati, 2010: 25-41).

Ibu sebagai tahap awal agar anak dapat tumbuh kembang efektif, dengan mencegah berbagai penyakit yang timbul pada anak maka ibu harus melakukan tindakan yang efektif yaitu berkunjung ke posyandu dengan mengimunisasi balitanya untuk mencegah cacat dan kematian pada balita, menimbangkan secara rutin ke posyandu agar ibu mengetahui tahapan tumbuh dan kembang anaknya, maka pengetahuan ibu tentang posyandu sangat penting bagi kesejahteraan anaknya (Ismawati, 2010)

Kunjungan ke posyandu sesuai jadwal yang sudah di tetapkan oleh posyandu dan minat untuk berkunjung harus timbul pada ibu karena masa balita ini merupakan masa yang menentukan dalam tumbuh kembangnya. Ibu sebagai salah satu orang yang penting dalam pengasuhan balita harus meluangkan waktu dalam melakukan kunjungan posyandu.

\section{METODE PENELITIAN}

Jenis penelitian ini adalah kuantitatif dengan pendekatan koresional, Dalam penelitian ini menggunakan bentuk "cross sectional" (Sugiyono, 2011). Sampelnya adalah semua Ibu balita yang datang di Posyandu Desa Nawangan Kecamatan 
Nawangan Kabupaten Pacitan Bulan Februari 2017 yang memenuhi kriteria inklusi dan diambil menggunakan teknik Accidental Sampling.

Variabel bebas dalam penelitian ini adalah pekerjaan ibu balita dan variabel terikat penelitian ini adalah minat ibu Balita dalam kunjungan Posyandu. Instrumen yang digunakan dalam penelitian ini adalah kuesioner tertutup, dimana kuesioner tersebut dibuat sedemikian rupa sehingga responden hanya tinggal memilih atau menjawab pada jawaban yang sudah ada (Hidayat, 2009:98). Untuk menganalisa hubungan antar 2 variabel (independent) pekerjaan ibu balita dengan variabel (dependent) minat dalam kunjungan posyandu balita, menggunakan uji korelasi chi square. Penulis menggunakan bantuan program komputer yaitu SPSS 18 for Windows pada taraf signifikan 0,05 . Jika $\leq 0,05 \mathrm{H} 0$ ditolak dan jika >0,05 maka H0 diterima.

\section{HASIL PENELITIAN}

1. Pekerjaan Ibu Balita

Tabel 1

Distribusi Responden Berdasarkan

Karakteristik Pekerjaan Ibu

\begin{tabular}{llcl}
\hline No & Pekerjaan & Jumlah & $\%$ \\
\hline 1 & Bekerja & 51 & 61.4 \\
\hline 2 & Tidak Bekerja & 32 & 38.6 \\
\hline & Jumlah & 83 & 100 \\
\hline
\end{tabular}

Sumber: Kuesioner 2017

Berdasarkan tabel diatas, dari 83 responden yang diteliti didapatkan sebagian besar 51 responden $(61,4 \%)$ ibu balita bekerja, dan hampir setengahnya 32 responden $(38,6 \%) \mathrm{ibu}$ balita tidak bekerja.

2. Minat Kunjungan Posyandu Balita Tabel 2

Distribusi Responden Berdasarkan Karakteristik Minat Ibu

\begin{tabular}{llcl}
\hline No & Minat & Jumlah & $\%$ \\
\hline 1 & Positif & 12 & 14,5 \\
\hline 2 & Negatif & 71 & 85,5 \\
\hline & Jumlah & 83 & 100 \\
\hline
\end{tabular}

Sumber : Kuesioner 2017

Berdasarkan tabel diatas, dari 83 responden yang diteliti didapatkan sebagian besar 71 responden $(85,5 \%)$ dengan minat yang negatif, sedangkan sebagian kecil 12 responden (14,5\%) dengan minat yang positif.

3. Hubungan Pekerjaan Ibu dengan Minat Kunjungan Posyandu Balita

\section{Tabel 3}

Hubungan Pekerjaan Ibu dengan Minat Kunjungan Posyandu Balita Di Desa Nawangan Pacitan

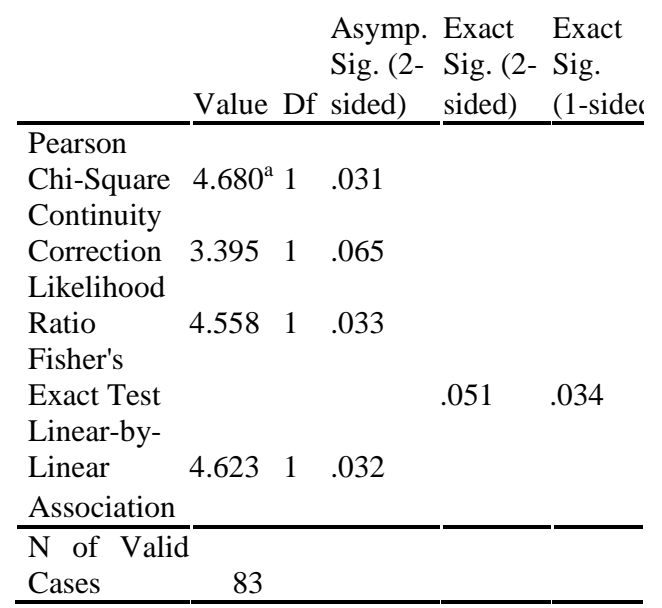

Berdasarkan hasil uji statistik dengan chi square menggunakan SPSS 20.0 diperoleh hasil bahwa $p$ value $=0,031$ sehingga nilai $p<a 0,05$ sehingga dinyatakan Ho ditolak $\mathrm{H} 1$ diterima yang berarti ada Hubungan pekerjaan ibu dengan Minat Kunjungan Posyandu Balita di Desa Nawangan Kecamatan Nawangan Kabupaten Pacitan.

\section{PEMBAHASAN}

1. Pekerjaan Ibu Balita

Berdasarkan hasil penelitian dari 83 responden yang diteliti didapatkan sebagian besar 51 responden $(61,4 \%)$ ibu balita bekerja, dan hamper setengahnya 32 responden $(38,6 \%)$ ibu balita tidak bekerja. Hal tersebut disebabkan oleh hampir seluruhnya 69 responden $(83,1 \%)$ berpendidikan dasar, sebagian kecil 10 responden (12\%) berpendidikan menengah, dan 4 responden $(4,8 \%)$ berpendidikan tinggi. Sehingga dengan pendidikan yang menengah dan tinggi (SMA dan DIII, S1), ibu balita akan lebih mementingkan pekerjaannya untuk menunjang status keluarganya dan 
tidak ada waktu luang untuk mengikuti kegiatan posyandu balita.

$$
\text { Sesuai dengan pendapat }
$$

Notoatmodjo (2012), tingkat pendidikan (dasar, menengah, dan tinggi) akan mempengaruhi dalam mendapatkan pekerjaan. Seseorang yang telah mendapatkan pendidikan diharapkan dapat lebih baik dalam kepribadian, kemampuan dan ketrampilannya agar bisa lebih baik dalam bergaul dan beradaptasi di tengah-tengah kehidupan masyarakat, sehingga mempermudah seseorang dalam memenuhi kebutuhan hidupnya.

Berdasarkan hasil penelitian dapat ditarik opini bahwa pekerjaan sangat dipengaruhi oleh faktor pendidikan. Sehingga diharapkan dengan memberikan motivasi atau penyuluhan pada ibu balita yang bekerja tentang pentingnya melakukan kunjungan posyandu dengan meluangkan waktunya dalam kegiatan posyandu balita.

2. Minat Kunjungan Posyandu Balita

Berdasarkan hasil penelitian dari 83 responden yang diteliti didapatkan sebagian besar 71 responden $(85,5 \%)$ dengan minat yang negatif, sedangkan sebagian kecil 12 responden (14,5\%) dengan minat yang positif. Hal tersebut disebabkan oleh hampir seluruhnya 69 responden $(83,1 \%)$ berpendidikan dasar, sebagian kecil 10 responden (12\%) berpendidikan menengah, dan 4 responden $(4,8 \%)$ berpendidikan tinggi. Sehingga dengan pendidikan yang rendah/ dasar (SD, SMP) akan memiliki pemahaman yang kurang tentang pentingnya kegiatan posyandu balita.

Minat adalah suatu rasa lebih suka dan rasa keterkaitan pada suatu hal atau aktivitas, tanpa ada yang menyuruh. Minat pada dasarnya adalah penerimaan akan suatu hubungan antara diri sendri dengan sesuatu di luar diri. Semakin kuat atau dekat hubungan tersebut, semakin besar minat (Slameto, 2015: 180). Salah satu faktor dari yang mempengaruhi minat ibu mengunjungi posyandu adalah tingkat pendidikan, pendidikan itu sendiri adalah segala penglaman belajar yang berlangsung dalam segala lingkungan dan sepanjang hidup, dimana pendidikan akan mempengaruhi pertumbuhan individu (Andryana, 2015: 12 ).

Tingkat pendidikan (dasar, menengah, dan tinggi) akan mempengaruhi dalam mendapatkan pekerjaan. Seseorang yang telah mendapatkan pendidikan diharapkan dapat lebih baik dalam kepribadian, kemampuan dan ketrampilannya agar bisa lebih baik dalam bergaul dan beradaptasi di tengahtengah kehidupan masyarakat, sehingga mempermudah seseorang dalam memenuhi kebutuhan hidupnya (Notoatmodjo, 2012).

Dari hasil penelitian dapat ditarik opini bahwa minat dipengaruhi oleh faktor pendidikan. Sehingga diharapkan dengan memberikan penyuluhan pada ibu balita khususnya yang berpendidikan dasar untuk meningkatkan minat melakukan kunjungan posyandu, karena dengan kegiatan posyandu merupakan salah satunya upaya dalam pengawasan terhadap anaknya dalam pertumbuhan dan perkembangannya.

3. Hubungan Pekerjaan Ibu dengan Minat Kunjungan Posyandu Balita di Desa Nawangan Kecamatan Nawangan Kabupaten Pacitan

Berdasarkan hasil tabulasi silang dari 83 responden didapatkan pada ibu balita yang bekerja dengan minat negatif 47 responden $(92,2 \%)$ terdiri daripada ibu balita yang bekerja dengan minat positif 4 responden $(7,8 \%)$. Pada ibu balita yang tidak bekerja dengan minat negatif 24 responden $(75 \%)$, pada ibu balita yang tidak bekerja dengan minat positif 8 responden $(25 \%)$.

Berdasarkan hasil uji statistik dengan chi square menggunakan SPSS 20.0 diperoleh hasil bahwa $p$ value $=$ 0,031 sehingga nilai $p \quad<a \quad 0,05$ sehingga dinyatakan Ho ditolak H1 diterima yang berarti ada Hubungan pekerjaan ibu dengan Minat 
Kunjungan Posyandu Balita di Desa Nawangan Kecamatan Nawangan Kabupaten Pacitan, dan Correlation Coefficient $=0,231$ yang berarti tingkat keeratan rendah.

Berdasarkan hasil penelitian yang telah dilakukan oleh Paridah (2014), tentang Hubungan pengetahuan, sikap dan status pekerjaan ibu balita dengan frekuensi penimbangan balita di Wilayah Kerja Puskesmas Pamandati Kabupaten Konawe Selatan. Metode penelitian yang digunakan adalah survey analitik dengan rancangan Cross sectional study. Sampel pada penelitian ini yaitu ibu yang memiliki balita yang terdaftar di buku register penimbangan balita, berkunjung dan menimbang ke posyandu di wilayah kerja puskesmas pamandati sebanyak 87 responden.

Teknik pengambilan sampel menggunakan purposive sampling. Analisis statistik menggunakan uji Chi Square. Hasil penelitian menunjukkan ada hubungan yang signifikan antara pengetahuan $(\rho \quad$ Value $=0,014)$ dan sikap ( $\rho$ Value $=0,025$ ) ibu balita dengan frekuensi penimbangan balita ke posyandu. Serta tidak ada hubungan yang signifikan antara status pekerjaan ( $\rho$ Value $=0,060)$ ibu balita dengan frekuensi penimbangan balita ke posyandu. Disarankan kepada petugas kesehatan untuk terus memantau pertumbuhan dan perkembangan balita, serta meningkatkan sosialisasi dan motivasi kepada ibu balita agar lebih aktif berkunjung ke Posyandu.

Faktor-faktor yang mempengaruhi minat meliputi : umur, pendidikan, pekerjaan dan jarak rumah (Andryana, 2015). Sedangkan faktor-faktor yang mempengaruhi kunjungan ibu balita ke posyandu diantaranya pengetahuan ibu, umur balita, pekerjaan ibu, jarak rumah, dan fasilitas (Agustina, 2013: 02). Minat adalah suatu rasa lebih suka dan rasa keterkaitan pada suatu hal atau aktivitas, tanpa ada yang menyuruh. Minat pada dasarnya adalah penerimaan akan suatu hubungan antara diri sendri dengan sesuatu di luar diri. Semakin kuat atau dekat hubungan tersebut, semakin besar minat (Slameto, 2015: 180).

Berdasarkan hasil penelitian dapat ditarik opini bahwa hasil penelitian diatas didapatkan minat kunjungan posyandu balita di pengaruhi oleh factor pekerjaan ibu. Sehingga diharapkan dengan dilakukan penyuluhan untuk meningkatkan minat melakukan kunjungan posyandu merupakan untuk bimbingan dan pengawasan terhadap anaknya. Kebutuhan anak balita dalam masanya adalah kebutuhan fisik-biomedis ("ASIH") (penimbangan secara teratur, imunisasi, pengobatan), kebutuhan emosi dan kasih saying ("ASUH") kasih sayang orang tua akan meningkatkan ikatan yang erat, kebutuhan akan stimulasi dan mental ("ASAH") akan mengembangkan kecerdasan, kemandirian dan kepribadian.

\section{KESIMPULAN}

1. Pekerjaan ibu balita di Desa Nawangan Kecamatan Nawangan Kabupaten Pacitan, sebagian besar 51 responden $(61,4 \%)$ ibu balita bekerja.

2. Minat kunjungan posyandu ibu yang memiliki balita di Desa Nawangan Kecamatan Nawangan Kabupaten Pacitan, sebagian besar 71 responden $(85,5 \%)$ dengan minat yang negatif.

3. Ada Hubungan Pekerjaan Ibu dengan Minat Kunjungan Posyandu Balita di Desa Nawangan Kecamatan Nawangan Kabupaten Pacitan, $p$ value $=0,031$ sehingga nilai $p<a \quad 0,05$ sehingga dinyatakan Ho ditolak $\mathrm{H} 1$ diterima.

\section{SARAN}

1. Bagi Institusi

Diharap mampu dijadikan sebagai bahan pertimbangan, masukan, dan informasi untuk mengambil keputusan dalam upaya peningkatan pelayanan kesehatan dalam hal pentingnya posyandu balita bagi balita.

2. Bagi Profesi

Diharapkan dapat menjadi salah satu sumber informasi untuk untuk melakukan penyuluhan pada ibu balita 
dalam meningkatkan kunjungan posyandu.

3. Bagi Peneliti Lain

Guna menambah referensi dalam melakukan penelitian lebih lanjut tentang Hubungan Pekerjaan Ibu dengan Minat Kunjungan Posyandu Balita.

4. Bagi Ibu yang Memiliki Balita

Diharapkan mampu memberikan informasi mengenai pentingnya posyandu balita, guna memantau tumbuh kembang balita dan sebagai sarana mendapatkan informasi serta berkomunikasi kepada petugas kesehatan setempat.

\section{DAFTAR PUSTAKA}

Agustina, N. 2013. Faktor-Faktor yang Mempengaruhi Ibu Balita Tidak Berkunjung ke Posyandu studi di Desa Pamongan Kecamatan Guntur Kabupaten Demak. Jurnal kebidanan panti wilasa, (Online), Vol 4, No.1, diakses 10 Desember 2016

Andryana R. 2015. Minat Ibu Mengunjungi Posyandu di Wilayah Kerja Puskesmas Simpang Baru Kecamatan Tampan. Jom FISIP, (Online), Vol 2, No.2, Diakses 10 Desember 2016

Arikunto, S. 2010. Prosedur Penelitian Suatu Pendekatan Praktik. Jakarta: Rineka Cipta.

Azwar, S. 2007. Sikap Manusia Teori dan Pengukuranya. Yogyakarta: Pustaka Pelajar.

Chayatin, N. 2009. Ilmu Kesehatan Masyarakat: Teori dan Aplikasi. Jakarta:salemba medika.

Depkes RI.2004. Pandua Pengunaan Kartu Menuju Sehat (KMS) Balita Bagi Petugas Kesehatan. Jakarta. Dinas kesehatan jawa timur "profil kesehatan jawa timur tahun 2004"

Effendi, N. 1998. Dasar-dasar keperawatan kesehatan masyarakat. Jakarta: EGC

Idris, N. dkk. 2009. Minat Peternak Untuk Mengembangkan Ternak Sapi Di Kawasan Perkebunan Kelapa Sawit. 11, Nomor 2, (http://onlinejournal.unja.ac.id/indexp hp/humaniora/article/download/1917/ 1268,diakses tanggal 14 Desember 2016)

Ismawati, C. 2010. Posyandu (Pos Pelayanan Terpadu) dan Desa Siaga. Yogyakarta: Nuha Medika

Kementrian Kesehatan RI. 2011. Buku Panduan Kader Posyandu.

Muslihatun, WN. 2010. Asuhan Neonatus Bayi dan Balita. Yogyakarta: Fitra Maya

Notoatmodjo. 2003. Pendidikan Dan Perilaku Kesehatan. Jakarta: Rineka Cipta . 2007. Metode Penelitian Kesehatan. Jakarta: Rineka Cipta. 2010 Metode Penelitian

Kesehatan. Jakarta: Rineka Cipta. 2012. Metode Penelitian

Kesehatan. Jakarta: rineka cipta

Nursalam 2003. Konsep \& penerapan metode penelitian ilmu keperawatan: pedoman skripsi tesis dan instrumen penelitian keperawatan. Jakarta: Salemba Medika

2011 Konsep \& penerapan metode penelitian ilmu keperawatan: pedoman skripsi tesis dan instrumen penelitian keperawatan. Jakarta: Salemba Medika

Paridah, 2014. Hubungan Pengetahuan, Sikap, Dan Status Pekerjaan Ibu Balita Dengan Frekuensi Penimbangan Balita Ke Posyandu Di Wilayah Kerja Puskesmas Pamandati Kabupaten Konawe Selatan. Jurnal Fakultas Kesehatan Masyarakat Universitas Halu Oleo

Proverawati, A. 2009. Gizi Untuk Kebidanan. Yogyakarta: Nuha Medika.

Slameto. 2015. Belajar dan FaktorFaktor yang Mempengaruhi. Jakarta: Rineka Cipta.

Sugiyono, 2012. Statistika Untuk Penelitian. Bandung : Alfabeta

Suharso. 2005. Kamus besar bahasa Indonesia. Semarang: Widya Karya.

Sutrismang. 2010. Ketidak Aktifan Datang Ke Posyandu. (online),(http://unimusgdl.sutrismang5293-3. Bab2, diakses 10 Desember 2016). 